\title{
COMPUTER INTERACTIVE TEACHING TECHNOLOGY FOR ELECTRONICS ENGINEERING UNIVERSITY
}

${ }^{1}$ Nguyen Thi Thanh, ${ }^{2}$ Le Huy Tung, ${ }^{3}$ Nguyen Xuan Lac

${ }^{1}$ Teacher Thuy Loi University, Hanoi University of Science and Technology, Viet Nam

${ }^{2,3}$ Hanoi University of Science and Technology, Viet Nam.

*Corresponding Author: Nguyen Thi Thanh

${ }^{1}$ Corresponding Author Email: thanhnguyen@tlu.edu.vn

Article Received: 11-07-19 Accepted: 20-08-19 Published: 05-09-19

Licensing Details: Author retains the right of this article. The article is distributed under the terms of the Creative Commons Attribution-NonCommercial 4.0 License

(http://www.creativecommons.org/licences/by-nc/4.0/) which permits non-commercial use, reproduction and distribution of the work without further permission provided the original work is attributed as specified on the Journal open access page.

\begin{abstract}
Virtual reality technology currently tends to develop and apply strongly in all areas of social life. Therefore, the application of virtual reality technology in education and training is becoming more and more urgent. If we know how to effectively exploit and apply virtual reality technology to the design of the education and training process, the teaching of teachers and the acquisition of learners' knowledge will become easy, born dynamic. However, in order to achieve high efficiency, it is necessary to have a creative, flexible and appropriate application based on the actual conditions of each field, each school, the learning ability of learners, the ability to use using modern teaching facilities of teachers, specific subjects.
\end{abstract}

Keywords: Development Education, Virtual Interaction, Mechatronics, Virtual Interactive Teaching, Improving Teaching Quality.

\section{INTRODUCTION}

This topic researches and teaches virtual interaction for some subjects of the mechatronics industry. Surveying the status of online students at some university walls in Hanoi and Thai Nguyen on the application of virtual interaction in teaching. Survey students after the virtual interaction of industrial robotics at Thai Nguyen University of Industry.

So far, this technology has been developed and applied in many fields: military, health, entertainment, etc. With the strong development of science and technology, researchers have come up with some new approaches to this type of application, one of which is virtual desktop VR virtualization technology. This type of virtual reality technology allows creating 
applications with reasonable production costs and meeting most of the needs of users. Virtual reality technology is processed on the computer system, simulated images are displayed on the computer screen and participants interact with the content via keyboard, mouse and some function keys On the keyboard depending on the specific virtual reality application is created. Therefore, this technology is used by many countries in creating applications in many fields, including education and training.

\section{LITERATURE REVIEW}

Interactive teaching methods are methods to apply the theory of interactive teaching (triad of principles, triad of behaviors) and use interactive teaching facilities, so that the teaching process is basically learners' learning process.

Interactive teaching is divided into 3 types: non-role-playing, role-playing and role-playing. In reality, schools currently use interactive non-role-playing interactive teaching. Without lack of interactive interactive teaching and especially immersive interactive teaching, there is almost no.

Non-immersive interactive teaching is currently being used: as a virtual interactive software application and a demonstration for students to observe as a virtual interaction tool to visualize knowledge for learners to can be easily visualized. For example, an inverted motor, or a divergent or engine engine, etc. There is a lot of knowledge that if you can interact virtually, students can easily understand and grasp knowledge easily.

Teaching immersive interactive learning is the learner who participates in a part of that teaching process, with a lecture with a large screen system surrounding the user to create a sense of integration into the 3D virtual environment.

Role-playing interactive teaching learners fully integrate into the activities in it, do not feel like an observer in the open. Learners experience real life in a virtual environment, thanks to specialized display sets (HMD, BOOM). With immersive teaching methods, learners are not allowed to observe but can listen, move, move and control the activities of devices and structures. Learners not only learn but also understand the structures and principles that work right in the classroom.

In the current trend in the world towards virtual interactive teaching methods and is evaluated as teaching methods to stimulate multi-senses for learners. Help learners enthusiastically study, stimulate autonomy and creativity, as well as understand the nature of phenomena.

The author conducted online surveys for students in many schools

Different universities such as Hanoi University of Science and Technology, University of Water Resources and University of Communication

Transport, Thai Nguyen University of Industrial Technology, Hanoi University of Industry Online survey and obtained results according to the following link:

https://docs.google.com/forms/d/e/1FAIpQLSckkZDpNZ--7UpAWQBgnwhPM1PC-

\section{Cx0pdJeUfyc1x-bHwOZUQ/viewform}

\section{Purpose}

Surveys to understand the reality of virtual interactive teaching at universities. The author uses online surveys because he can reach more quickly with more subjects at universities.

Survey of lecturers' opinions about virtual interactive teaching page for mechatronics industry. 


\section{Respondents}

Subjects surveying students at Hanoi University of Science and Technology, Posts and Telecommunications Academy, University of Transport and Communications, Thai Nguyen Industrial Technology University, Hanoi University of Industry.

The initial results are very well judged to be a virtual interactive application for industrial robotics in particular and for the subjects of mechatronics in general.

\section{Content}

On the theoretical basis of interactive teaching, virtual interactive teaching and awareness of virtual interaction, virtual reality software, assessment of subjects using virtual interactive teaching methods, thesis Central survey:

- For students: Surveying the situation of applying virtual interactive technology to teaching, Surveying student opinions on industrial robotics, surveying students' ideas about how to bring virtual interaction into teaching, Surveying student opinions about knowledge about virtual interaction

- For Lecturers: Survey the status of virtual interactive applications in teaching teaching.

- Survey method: The main method to conduct the survey is to use online survey forms for students of universities, paper survey forms for students participating in virtual interactive classes.

In particular, questions designed in questionnaires are sent to lecturers and students at universities. The questionnaire system is structured to include open, closed, multiple-choice questions with clear, concise, easy-to-understand content.

When surveyed about 450 opinions, students who knew virtual reality had $11 \%$ of their opinions through the press, $31 \%$ via the internet, $40 \%$ through games, $9 \%$ via television and $9 \%$ knew through other channels.

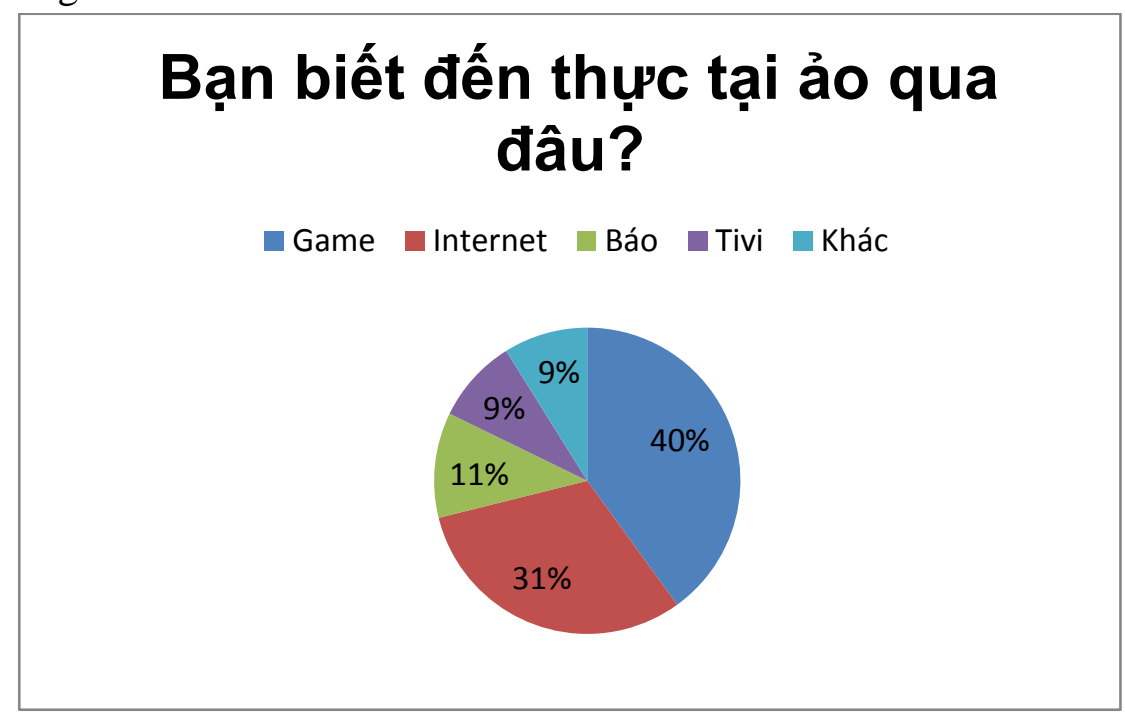

Figure 1: Survey of virtual consciousness awareness

Virtual interactive environment is a condition for effective industrial robotics teaching. Need to build a virtual interactive environment and determine in what extent the classroom is responsive. A VR system is required: software, hardware, networking, users and applications. Among them, the three most important parts are: hardware, applications, software. In a survey of pre-school students about industrial robotics, $57.1 \%$ of students 
rated the subject difficult to understand, $32.1 \%$ rated it difficult to understand, and only $10.7 \%$ of the students rated it normal.

Table 1

Assessment of Industrial Robotics Subjects

\begin{tabular}{lcccc}
\hline \multicolumn{1}{c}{ Content } & $\begin{array}{c}\text { Difficult to } \\
\text { understand }\end{array}$ & $\begin{array}{c}\text { Hard to } \\
\text { understand }\end{array}$ & Normal & $\begin{array}{c}\text { Easy to } \\
\text { understand }\end{array}$ \\
\hline $\begin{array}{l}\text { Assessment of industrial robotics } \\
\text { subjects }\end{array}$ & $32,2 \%$ & $57,1 \%$ & $10,7 \%$ & 0 \\
\hline
\end{tabular}

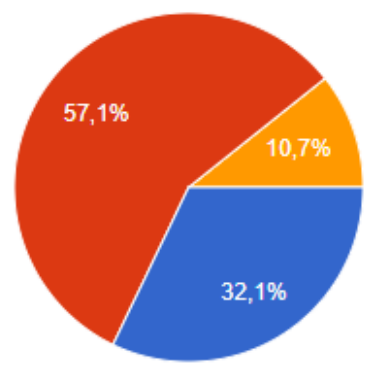

Figure 2: Survey of students assessing industrial robotics subjects

When surveyed, students learned about the TTA branch at any level, 200 ideas at the entry level, 140 ideas at the semi-role level and 110 experiences at the non-entry level. jar

\section{METHODOLOGY AND RESULTS}

The author directly conducted the lecture for both experimental and control classes. In both subjects, we have invited a number of teachers with professional qualifications, teaching experience and enthusiasm, with the movement of innovation of teaching Virtual interaction facilities and some teachers with pedagogical skills. Come to the office to learn from the experience.

At the end of the teaching session, hand out the test questionnaire to collect information about the level of students learning. Then organize a workshop with teachers who are invited to participate in the review, evaluate and contribute ideas for each lecture according to the way of virtual interaction used.

The degree of positive impact of the psychological environment in teaching Virtual interaction

1 / Open-minded, friendly and friendly teacher relationship. Learners are encouraged to exchange and share with the teacher about Virtual interaction programs for learning and life.

2 / The relationship between class members is friendly, close and close.

3 / Cultural, ideological and conceptual factors of learners do not conflict and affect the general learning process.

Table 2

\begin{tabular}{llllllllll}
\multicolumn{8}{c}{ Post test results } & Number of students gaining Xi) \\
\hline Class & $\mathrm{N}$ & 3 & 4 & 5 & 6 & 7 & 8 & 9 & medium \\
control & 22 & 1 & 4 & 5 & 6 & 4 & 1 & 1 & 5,7 \\
experiment & 22 & 0 & 2 & 3 & 5 & 7 & 3 & 2 & 6,54 \\
\hline
\end{tabular}




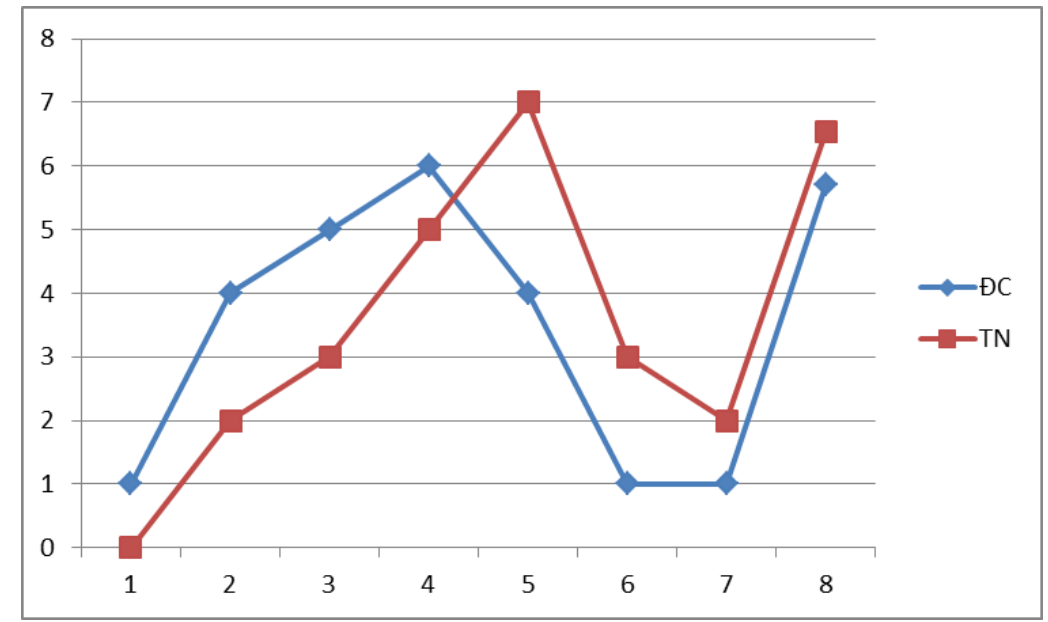

Figure 3: The frequency of progressive convergence students get Xi

Table 3

\begin{tabular}{llllllll}
\multicolumn{7}{l}{ Frequency table (percentage of students } & who get Xi) \\
\hline $\begin{array}{l}\text { Class } \\
\text { control }\end{array}$ & 3 & 4 & 5 & 6 & 7 & 8 & 9 \\
& 4.5 & 18.2 & 22.7 & 27.4 & 18.2 & 4.5 & 4.5 \\
experiment & 0 & 9.1 & 13.6 & 22.7 & 31.9 & 13.6 & 9.1 \\
\hline
\end{tabular}

Table 4

Variance, standard deviation, coefficient of variation for experimental class

\begin{tabular}{ccccc}
\hline $\mathbf{X i}$ & $\mathbf{F i}$ & $\left(\mathbf{X i}-\overline{X_{T N}}\right)$ & $\left(\mathbf{X i}-\overline{X_{T N}}\right)^{\mathbf{2}}$ & $\left(\mathbf{X i}-\overline{X_{T N}}\right)^{\mathbf{2}} \mathbf{F i}$ \\
\hline 3 & 0 & $-3,54$ & 12,53 & 0 \\
4 & 2 & $-2,54$ & 6,45 & 12,9 \\
5 & 3 & $-1,54$ & 2,37 & 7,11 \\
6 & 5 & $-0,54$ & 0,29 & 1,45 \\
7 & 7 & 0,46 & 0,21 & 1,47 \\
8 & 3 & 1,46 & 2,13 & 6,39 \\
9 & 2 & 2,46 & 6,05 & 12,1 \\
$\sum$ & & & & 41,42 \\
\hline
\end{tabular}

Variance: $\delta^{2}{ }_{\mathrm{TN}}=\frac{1}{N-1} \sum\left(X i-{\overline{X_{T N}}}^{2} \mathrm{Fi}=\frac{1}{22-1} 47,4=1,97\right.$

Standard deviation: $\delta_{T N}=\sqrt{\delta^{2}} \mathrm{TN}=1,4$

Variable coefficient: $\gamma_{T N}(\%)=\frac{\delta_{T N}}{\overline{X_{T N}}} 100(\%)=\frac{1,4}{6,54} 100(\%)=21,4 \%$

Based on experimental results The author draws some of the following comments:

- Awareness of students in experimental classes is aroused and shown clearly. Dynamic hours, comfortable to draw attention and create debate building lessons thanks to the virtual interaction of the lesson. 
- The quality of mastering, applying knowledge and intellectual activity capacity of the experimental students is higher than that of the control class, which is reflected in the average score of the experimental class in both lessons is high. than the control class.

- The ability to reason, express TTA program in virtual interaction language and understanding of experimental class is higher than that of control class.

\section{Expert opinion}

Analyzing the results of assessing the positive and effective of learners when participating in pedagogical interactions

The capacity of students to implement interactions between learners and teachers in experimental classes is higher than that of control classes, in particular: students assess the ability to apply orientations and solutions. $80 \%$ of those who taught to solve TTA program in experimental class, $58.78 \%$ in control classes; In assessing the ability to ask questions, setting up TTA program, the questions about TTA programs studying with lecturers in the experimental class are $73.6 \%$, while the control classes are only $61 \%$; .

The capacity of students to implement interactions between learners and the environment in the experimental class is higher than that of the control class, for example: students assessed as capable of working in experimental classes are $90 \%$, while the control class is $77 \%$; The assessment has the capacity of searching, exploiting and using electronic data or digital data in the experimental class is $75 \%$, while the control class is $58 \% ; 82.48 \%$ of the capacity of accessing and exploiting information and data on the internet in experimental class, while this rate in the control class is only $51.38 \%$.

\section{DISCUSSIONS}

Currently, the research on information technology application in training mechatronics students. A virtual interactive program of the era but still single and incomprehensive, therefore, the effective effect is not high. The State needs to have key investment projects, research and deploy synchronously the application of information technology in training mechatronics students.

Due to the virtual interactive nature of the experiment, the requirement of virtual interaction is designed to be very simple in structure and usage, accurate and sufficient in content. In addition, in terms of art as well as interactive virtual teaching using techniques in design, virtual interaction must create a professional and serious feeling for users. Must have instructions for user operations as well as control tools must be clear.

\section{CONCLUSION}

From the results obtained by the above methods, the following conclusions can be drawn:

1. The construction of virtual interactive teaching in interactive virtual teaching in industrial robotics has contributed to increasing the interest, positivity, and self-study of students, which has brought about remarkable results about the level of knowledge, developing thinking, teaching virtual interaction to present and express the virtual interactive program of students.

2. The author explores student opinion after school to evaluate the initial hypotheses about interactive virtual teaching methods that are effective for school hours. 
3. In order to apply most lectures using virtual interactive teaching methods, teachers need to foster and improve professional skills and computer skills, and at the same time be passionate about virtual interactive teaching, with the movement to improve teaching methods. On the other hand, there should be coordination of mobilized investment of departments and management levels.

\section{References}

Alvarez, M. (2006). The use of virtual worlds in high school education. Second Life and school, Retrieved December 6, 2007:

Artnet (2009). Artist's home of Kehind Wiley. Retrieved March 20, 2009: from http://www.artnet.com/awc/kehinde-wiley.html.

Ausburn, L J. \& Ausburn. F. B. (2004). Desktop virtual reality: A powerful new technology for teaching and research in industrial teacher education. Journal of Industrial Teacher Education, 41(4). Retrieved March 20, 2009,: http://scholar.lib.vt.edu/ejournals/JITE/v41n4/ausburn.html.

Benjamin Z.P., Marin, M.M., \& Perez, E.D. (2007). Dveloping a Virtual Environment for Safety Training. Electronics, Robotics and Automotive Mechanics Conference. Morelos 2007. pp. $545-550$.

Benzina, M. Toennis, G. Klinker, and M. Ashry. "Phone-based motion control in vr: analysis of degrees of freedom." in CHI'11 Extended Abstracts on Human Factors in Computing Systems. ACM, 2011, pp. 1519-1524.

Breen P.T,., \& Scott, W.G. (1995). Virtual Reality Applications in T\&D Engineering. Rural Electric Power Conference, Nashville. 1995, pp. B5/1 --B5/6.

Burdea, G. C., \& Coiffet, P. (2003). Virtual reality technology,Inc. n.d.

Byrne, C. (1993). Virtual reality and education. In proceedings of IFIP WG3.5International workshop conference. n.d. http://www.ucop.edu:8080/display/SecondLife/Articles+and+Papers.

Sampaio, A.Z., Henriques, P.G., \& Martinsirtual., M.P. (2010). Reality Technology Used in Civil Engineering Education. The Open Virtual Reality Journal, 2, 18-25, 2010. 